\title{
China's Public Hospitals and a Preliminary Design for Them to Shoulder the Responsibility of Commonweal
}

\author{
Fengrong Liu \\ Center for China Fiscal Development \\ Central University of Finance and Economics \\ Beijing, China \\ Zhengxia Tang \\ School of Economics \\ Central University of Finance and Economics \\ Beijing, China
}

\begin{abstract}
China has been dedicating to public hospital reforms in recent years. The social responsibility of public hospitals is discussed and needs to design appropriate policy. In this paper, we propose connotation of the commonweal goal to distinguish it from a simple non-profitability notion. Several preconditions are listed in this paper, including pharmacy separation, restrain of retrospective payment, promoting primary care, enhancing budget and accountability information disclosure. Prudent choice of the suitable mode still needs to be made based on the current situation of China.
\end{abstract}

Keywords: public hospitals, responsibility of commonweal, non-profitability, modes choice

\section{Introduction}

Commonweal-oriented mechanism is one of the most important goals of public hospital reforms in China, calling for a series of adjustments including funding, reimbursement, service supply, motivation, management and so on. However, there is still no consensus of this mechanism among the public, the government or the scholars. Current study on this topic in China mainly takes non-profitability as the core of commonweal for public hospitals. Lan\& Chen (2010) argues that the commonweal responsibility of public hospitals is to provide public health services, medical services, education and research to the public rather than pursuing profit. Meanwhile, some research identifies the responsibility by specific services or indicators. Yu (2011) holds that three aspects should be involved in the connotation, the first is public services like medical services in disaster relief and public health services; the second is service efficiency in the hospitals; the third is appropriate treatment, such as average treatment fee and drug proportion in total expenditure.

In terms of the way to enhance the commonweal function of public hospitals in China, many researchers believe that the government should take the responsibility to increase funds (Lan, 2010; Dong, 2010; Zheng, 2009; Zhao, 2011; Zhang, 2008). In their opinion, the defect of public finance is the first problem to be solved. Besides, other measures are also propose, including more strict supervision on public hospitals ( $\mathrm{Hu}$, 2010; Zhang, 2008), transferring management power from the government to public hospitals (Dong, 2010), financial transfer mechanism of health investment (Chen, 2011), decreasing the number of public hospitals (Hu, 2010), government purchase of medical services (Xing, 2010), regional medical planning (Xing, 2010), separation between revenue and expenditures (Zheng, 2009), etc.

In summary, limitations exist in previous studies on the social responsibility of public hospitals. First, the definition of public hospitals' commonweal responsibility is not identical to non-profitability or some resulting indicators. Second, increasing public finance to the hospitals is now the acknowledged measure to enhance commonweal although there are no certain correlations between them. We believe that a pathway should be designed to strengthen the social responsibility of public hospitals in China, starting from clearly realization of the goal to several relating policy designs as the cornerstone. A final complete system can be established step by step rather than heavily depending on government funds or limitations on hospital revenue. 


\section{The commonweal responsibility of public hospitals}

\subsection{Commonweal responsibility and non-profitability}

For decades, marketization was a tendency for public hospitals in China to release the government finance burden and motivate the hospitals. Public hospitals are requested to operate and be accountable for their own gains and losses. Meanwhile, the prices of medical services are determined and controlled at very low level by government. With the deficiency of government financial support and low service price, public hospitals are led to pursue income maximization and gradually neglect the social responsibility. The size and service range of public hospitals are rapidly enlarged, resulting in resources accumulation, medical expenditure increase and more patients visits. Doctors' income is greatly linked to the price and amount of medical services and drugs, which induces the doctors to make more prescriptions.

Based on the background mentioned above, many people equal the commonweal responsibility of public hospitals as non-profitability. However, non-profitability is only one of the characteristics in the commonweal functions of public hospitals. Practices in other countries show that commonweal can involve equity, public welfare, medical aids, etc. And non-profitability doesn't only mean lower the price and cut doctors' service-related income. Public hospitals should also accept public (government, medical association or other NGOs) pricing, separate pharmacy income from the hospitals, take accountability and quality supervision.

\subsection{Different patterns to provide commonweal medical services}

Many countries have explored both the way to encourage public hospitals to shoulder social responsibilities and introduce market motivations to the system. Public hospitals in different countries show various modes to provide commonweal medical services because of the function or goal design by the government. These modes, illustrate different kinds of boundaries between commonweal services and marketization.

We define two modes of commonweal provision: one is the US Mode, public hospitals play the role as national security net to cater for the medical needs of the poor or the vulnerable group; the other one is the EU Mode such as Britain, France or Scandinavian countries, providing public medical resources to all the citizens through social insurance. These two modes throw light on the commonweal responsibility design of public hospitals in China. We should propose and answer several questions first. Who are the target groups of the commonweal? What are basic medical services provided by public hospitals? How to coordinate the relationship between social and commercial medical insurances? How to define relationship between primary care and public hospitals? What are the roles of government and market? The answers can hugely influence the final modes of commonweal provided by public hospitals.

\section{Preconditions for the responsibility of commonweal}

\section{1separating retail pharmacy from public hospitals}

In many countries, pharmacies inside public hospitals merely cater the demand of inpatients to store necessary drugs or medical consumables. Operating a pharmacy inside the hospital can be seen as a cost so that hospitals seek to efficient management. However, in China, pharmacy revenue occupies a large proportion of the public hospitals' total income. The policy to abolish markups on pharmaceuticals in public hospitals has been implemented since recent years. A pharmacy trusteeship way has been piloted in some areas, which remains controversial. Pharmacy trusteeship is not a real separation but still shows high profit seeking motive. In a case study of Nepal, a retail pharmacy was opened inside a public hospital, which ends up with strong motive to be profitable. No matter a pharmacy is separated by trusteeship in China or newly opened as trusteeship inside public hospitals in Nepal, both the pharmacy and the hospital tend to be greedy. It is necessary to redesign the function of pharmacy inside public hospitals to solve the over-prescription phenomenon in China.

\section{2 exploring new payment method to doctors instead of fee-for-service}

Economist Kenneth J. Arrow discusses the special characteristics of medical service in Uncertainty and the Welfare Economics of Medical Care: the uncertainty of the disease and the treatment result in more information occupied by doctors than the patients. Trust is essential in the relationship of doctors and patients. The medical advice should be independent of doctors' own interest. Retrospective payment, especially FFS, is the most popular payment method in Chinese public hospitals. Doctors' earnings are linked closely to the service they prescribe to patients, which is likely to overtreatment. 
No matter a government dominating or market-oriented medical system, doctors in public hospitals should be given an environment to make optimal treatment decision regardless of their own potential earnings. Even in highly market-oriented countries like the U.S., doctors working in public hospitals rarely earn their salary based on their medical revenue but mainly on seniority or job position. Pay-for-performance method has been introduced into hospitals regarding health outcomes like service quality, patient experience, education, etc.

\section{3 transparency of budget and accounting information}

"Soft budget" reflects the fact that public hospitals in China are not strictly directed by budget. The amount of public finance from the government should be specified by budget process, budget item and budget standard. Further monitor and observation should be made to follow the usage of the budget. When unreasonable or illegal implementation appears, measures should be taken to punish the hospital. Accounting information disclosureis another way to emphasize hospitals' responsibility. The transparency would encourage the hospital and the public to know better about the social responsibility of public hospitals and limit profit pursuing behavior. At the same time, information disclosure process can be a reference for government investment, insurance negotiation and even accepting public donation. Therefore, transparency of budget and accounting information is finally a guarantee for public hospital revenue.

\section{4 promoting primary care}

Enhancing social responsibility of public hospitals is not limited to the hospitals themselves but in demand of overall medical resources distribution. Under the national medical system, public hospitals and primary care institutions work to getheras the suppliers. First, the function setting and service range of primary care obviously influence the social responsibility of public hospitals. If the primary care system is so strong as gatekeeper, the patients public hospitals receive are transferred from primary care system. If there is no compulsory transfer from primary care, public hospitals will open to all the patients. In these circumstances, commonweal of the groups like the poor and the vulnerable is more likely to attract the attention of the public hospitals. Second, costs of commonweal services of public hospitals are much higher than primary care. To increase welfare of the entire society, strengthening primary care to provide commonweal services may be more efficient and economic.

\subsection{Choice between social security net and social insurance}

The present situation of public hospitals in China has not shown overt feature of neither the modes mentioned above. In other words, flexibility remains to choose between social security net mode and social insurance mode. In terms of the capacity of primary care and public hospitals, public hospitals are dominant in China's medical system, which enjoys more than 70 percent of the medical resources across the country. Comparatively, the primary care system is struggling to provide less and low-grade medical services. This pattern is similar to a social security net mode, which doesn't request compulsory first visit in primary care. The way to social security net would probably face fewer obstacles from primary care. However, China has successfully established its social medical insurance including New Rural Cooperative Medical System, Urban Residents Medical Insurance and Medical Insurance for Urban Employees. Social medical insurance has involved more than 95 percent citizens and coverage level has ever been increasing. It seems more like the social insurance mode but still needs further integration of the insurance and increase in the coverage standard.

\section{The future and challenges}

This paper preliminarily discusses some preconditions to the design of public hospitals responsibility of commonweal. Pharmacy separation and abolishment of FFS are two ways to lead hospitals and doctors away from merely pursuing profit. Others, such as budget, accounting and supervisions are also necessary methods to guarantee public hospitals' social responsibility. Mean while, we have to admit that either mode of public hospitals' social commonweal calls for specific preconditions. The choice remains to be done to direct the public hospital reforms in China.

\section{References}

Arrow K J. Uncertainty and the welfare economics of medical care[J]. The American economic review, 1963, 53(5): 941-973.

Chen, Y. F., \& Zhang, L. Public Health Welfare and Medical Financial Transfer Payment System Reform in Public Hospitals[J]. Chinese Hospital Management,2011,31(12):8-9. 
Dong, Y. P., Xia, M., Luo, W. J., \& Zhang, W. B. Policy Proposals for the Health Financial Transfer Payment System Based on the Public Welfare of Public Hospitals[J]. Chinese Health Economics,2010,29(09):2728.

Dong, Y. P., Wang, Y. Q., Lv, H., \& Luo, W. J. Analysis of Path Dependence of Public Welfare Regression of Public Hospitals under the New Medical Reform[J]. Chinese Hospital Management,2010,30(07):3-5.

$\mathrm{Hu}$, Z. B. Discussion on the Reasons for Public Welfare Lacking in Public Hospitals and its Countermeasures[J]. Medicine and Society,2010,23(05):40-42.

Kurt Darr. The Social Responsibility of Hospitals[J]. Hospital Topics, 1997, 75:1, 4-7. DOI: 10.1080/00185869709596468

Lan, Y. C., \& Chen, L. The Actualization of Commonwealth in Public Hospitals[J]. Chinese Health Quality Management,2010,17(03):92-96.

DOI : 10.13912/j.cnki.chqm.2010.03.007

Xing, X. H., \& Li, C. D.Public Finance Compensation Mechanism to Enhance the Nature of Public Welfare in Public Hospitals[J].Chinese Hospital Management,2010,30(11):1-2.

$\mathrm{Yu}, \mathrm{W}$. Public hospital reform in China: Public-interest nature, financial compensation and governance model. Chinese Journal of Health Policy, 2011,4(07):25-27.

Zhao, Y., Li, C. Y., Lu, Z. H., \& Huang, X. C. The Path of Realizing the Equilibrium between Public Welfare and Initiative in the Reform of Public Hospitals[J]. Modern Hospital Management,2011,9(06):7-10.

Zhang, M. Y. Thought on the Commonweal Nature of the Public Hospitals[J]. Chinese Health Economics,2008,27(12):8-11.

Zheng, D. X. The Difficulties and Countermeasures in Public Welfare Nature Implementation in Public Hospitals[J]. Modern Hospital Management,2009,7(05):18-21.

Zheng, D. X. On the difficulties and countermeasures in implementing public welfare nature of public hospitals from the perspective of new health reform program[J]. Chinese Journal of Health Policy,2009,2(08):2227. 